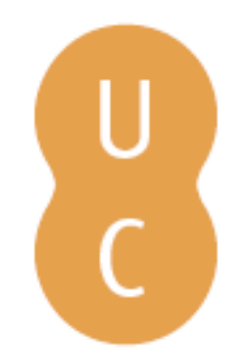

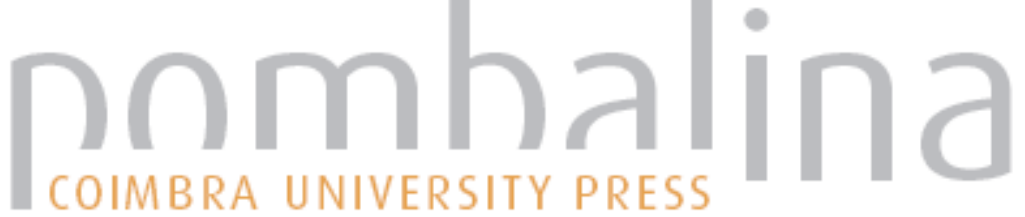

\section{Elegias da cultura na era da internet}

\author{
Autor(es): $\quad$ Fidalgo, António
}

Publicado por: Imprensa da Universidade de Coimbra

URL

persistente: URI:http://hdl.handle.net/10316.2/30725

DOI: $\quad$ DOI:http://dx.doi.org/10.14195/978-989-26-0574-6_5

Accessed : $\quad$ 26-Apr-2023 10:53:08

A navegação consulta e descarregamento dos títulos inseridos nas Bibliotecas Digitais UC Digitalis, UC Pombalina e UC Impactum, pressupõem a aceitação plena e sem reservas dos Termos e Condições de Uso destas Bibliotecas Digitais, disponíveis em https://digitalis.uc.pt/pt-pt/termos.

Conforme exposto nos referidos Termos e Condições de Uso, o descarregamento de títulos de acesso restrito requer uma licença válida de autorização devendo o utilizador aceder ao(s) documento(s) a partir de um endereço de IP da instituição detentora da supramencionada licença.

Ao utilizador é apenas permitido o descarregamento para uso pessoal, pelo que o emprego do(s) título(s) descarregado(s) para outro fim, designadamente comercial, carece de autorização do respetivo autor ou editor da obra.

Na medida em que todas as obras da UC Digitalis se encontram protegidas pelo Código do Direito de Autor e Direitos Conexos e demais legislação aplicável, toda a cópia, parcial ou total, deste documento, nos casos em que é legalmente admitida, deverá conter ou fazer-se acompanhar por este aviso.

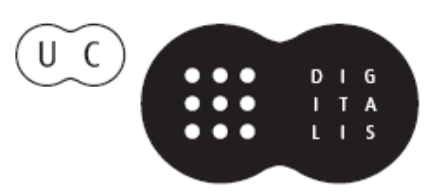




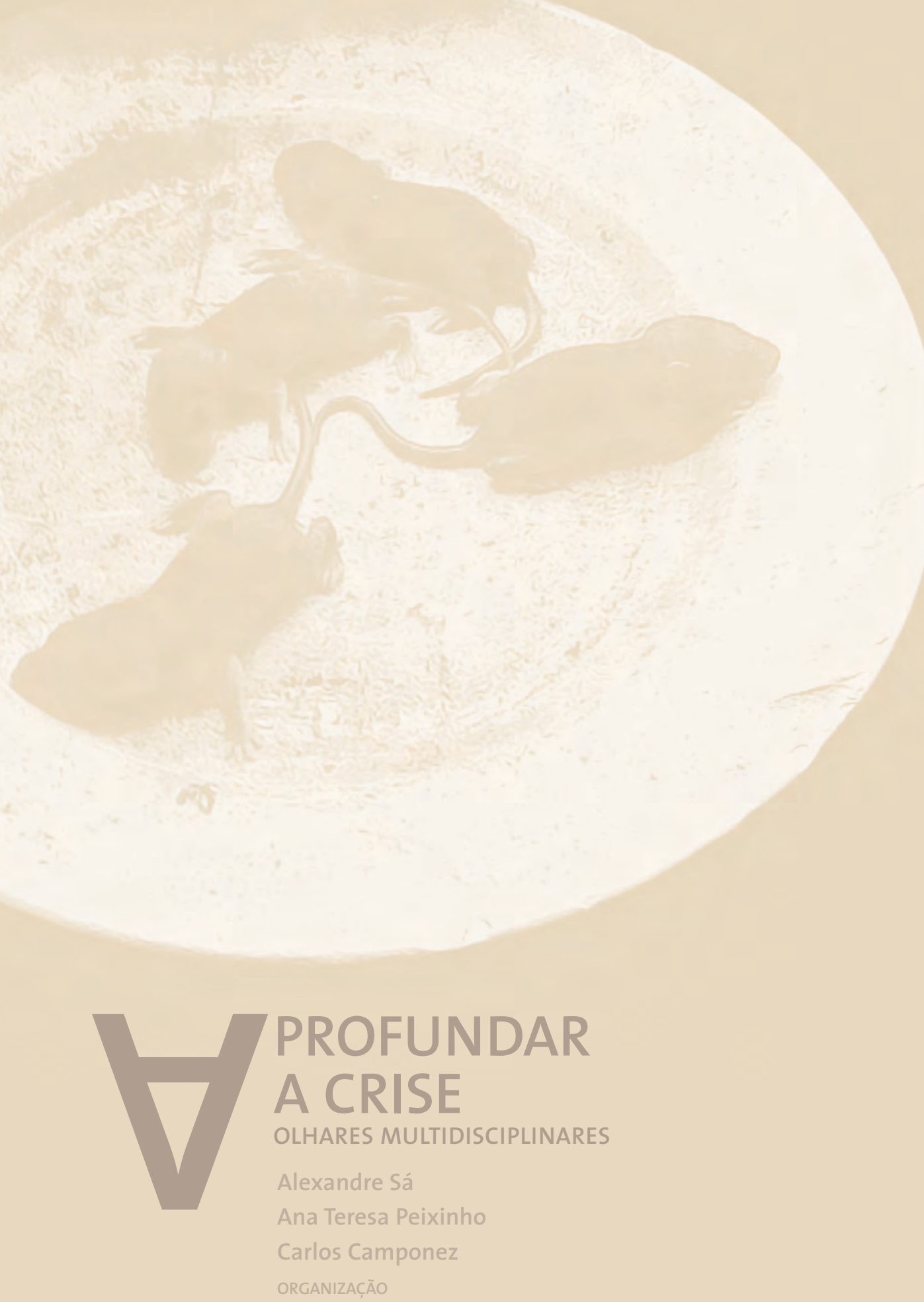


António Fidalgo

UBI

\section{Elegias da Cultura NA ERA DA INTERnet}

1. Desde sempre, ou pelo menos desde o Fedro de Platão, a emergência de um novo meio de comunicação deu azo a ditirambos e a elegias; uns vendo no novo meio a aurora de uma época mais capaz e mais inclusiva, outros achando que o novo meio representava a morte da cultura, preterindo o verdadeiro saber em favor de um conhecimento aparente, que se ficava pela rama. Foi assim com o surgimento da escrita, com a invenção da imprensa, com os meios eletrónicos de comunicação e hoje com a Internet. Enquanto muitos veem na Internet um poderoso meio de informação e de comunicação, com possibilidades quase ilimitadas de promover o saber e a cultura, outros acham que a Internet é um meio de estupidificação geral. O texto de Nicholas Carr "Is Google making us stupid?", publicado na revista Atlantic Monthly de julho de 2008 teve o mérito de enunciar o que era uma vaga sensação sentida por muitos, sobretudo pelos que faziam um uso diário da Internet, de que o acesso fácil e ilimitado (everywhere anytime) à informação não tinha correspondência numa melhor formação cultural e humanística. Com efeito, houve a perceção, nomeadamente por parte de docentes universitários, primeiro, que os jovens que nasceram já na era dos meios digitais, designados por digital natives, chegavam à universidade com lacunas graves na formação escolar e, em segundo lugar, que a própria forma de pensar estava sofrendo alterações profundas.

Nesse artigo, Nicholas Carr começa por constatar que nos últimos anos a sua maneira de pensar se modificara e que isso se notava desde logo na capacidade de leitura. Antes era-lhe muito fácil concentrar-se na leitura de um artigo ou de um livro e passar horas a fio seguindo uma longa narrativa ou as voltas intrincadas de uma linha de raciocínio. Agora, pelo contrário, verificava que a atenção se 
desviava ao fim de duas ou três páginas, que começava a ficar nervoso, impaciente, a perder o fio à meada, e à procura de qualquer outra coisa para fazer. E a explicação que encontra e aponta para esta alteração é a Internet. É que durante mais de uma década estivera online, navegando e fazendo buscas pelas grandes bases de dados online. Para um escritor como ele a Internet era uma dávida dos céus. Pesquisas que antes demoravam dias em canseiras por arquivos e bibliotecas, agora poderiam ser feitas comodamente em casa num computador ligado à Internet, levando minutos a obter as informações desejadas mediante algumas buscas efetuadas no Google. Além disso, a Internet oferecia-lhe tudo em um, comunicação por email, informação noticiosa, leituras de todo o tipo em múltiplos e diversos blogues, audição de podcasts e visionamento de vídeos. Era o meio universal, a bem dizer perfeito, que dispensava todos os outros. Só que tudo isto oferecido a um custo pesado: a perda das capacidades de concentração e de contemplação. Os meios não apenas passam a mensagem, os múltiplos e variados conteúdos, que alimentam o pensamento, eles alteram também o modo de pensar, de acordo com a doutrina de McLuhan.

Ler na Internet não é a mesma coisa que ler no velho papel. Afastando-se do meio impresso as pessoas deixaram de ler livros, e habituaram-se a passar os olhos (a fazer um scannning) pelos textos que passam continuamente pelos ecrãs dos computadores. É possível que hoje, na era da Internet, até se leia mais do que antes, na era da televisão, e isso graças a emails, a mensagens SMS, e à ubiquidade dos textos em milhares de blogues e de sítios na Internet. O problema é que é um outro tipo de leitura. A imediatez e a eficiência típicos da Internet debilitam a nossa capacidade de leitura lenta e atenta. Online tornamo-nos mais descodificadores de informação escrita do que verdadeiros leitores, prontos a imergir no texto e a seguir as múltiplas ramificações de pensamento a que nos leva a leitura.

O ponto crucial do artigo de Nicholas Carr é que o cérebro não é algo acabado, mas um órgão altamente maleável que se vai adaptando às realidades e desafios que o envolvem e que a Internet está de facto a alterar o modo de funcionamento do cérebro. É este ponto que é desenvolvido extensivamente no livro The Shallows: What the Internet is Doing to our Brains, publicado por Carr em 2010. Com a disseminação da Internet é a atividade intelectual do cérebro que se altera, ou seja os modos de como percecionamos e pensamos. 
Em vez de mergulhar nas águas profundas do conhecimento que os livros impressos nos ofereciam, ficaremos pelas águas baixas e salobras (the shallows) da informação online.

O tenor das posições de Nicolas Carr ecoa as preocupações de autores anteriores, como Neil Postman, We are amusing ourselves to death de 1986, e de Sven Birkerts, The Gutenberg Elegies de 1994. Na linha do pensamento de Marshall McLuhan de que os meios não se limitam a passar informação, mas que a condicionam fortemente, tanto dos lados dos emissores como dos recetores, estes autores consideram que a introdução dos meios eletrónicos e digitais de comunicação constituem uma rutura significativa nos processos pessoais e sociais de aprendizagem e de aculturação.

O livro de Postman, anterior à vulgarização da Internet graças à Web, é uma crítica contundente à televisão. A televisão não é um meio de informação, nem um meio de educação, mas, no fundo, um meio de entretenimento que converte tudo em diversão: a informação transforma-se em info-diversão (infotainment) e a educação em edu-diversão (edutainment). Na televisão sobrevivem apenas os programas que conseguem audiências e estas só se mantém se houver, de um modo ou de outro, entretenimento: sensacionalismo, curiosidade doentia, distração. Tudo o resto passa à categoria de aborrecimento. É da própria essência do meio televisivo entreter. Querer que sirva para outros fins, nomeadamente informativos e educativos, é não entender a natureza do meio audiovisual, que não é de todo apropriada a uma descrição e explanação conceptual. A televisão não é feita para discursos, nem para palavras, mas sim para imagens e telenovelas.

Kant distinguia conceitos e intuições pelo facto de os primeiros serem representações universais, válidos para qualquer objeto, facto ou circunstância, enquanto as intuições são individuais, cingidas ao aqui e agora da experiência. Ora as palavras são conceitos e os sons e as imagens são intuições, pelo que a natureza audiovisual e eo ipso intuitiva da televisão não se compagina com discursos ou raciocínios longos.

Ao mesmo tempo que crítica à televisão, o livro de Postman é também uma elegia da mente tipográfica, das capacidades perdidas de concentração e de raciocínio que caracterizavam os discursos públicos no século XIX. Se antes do advento das tecnologias de imagem, cinema e televisão, oradores e ouvintes eram capazes de aguentar horas seguidas os múltiplos debates que marcavam 
as campanhas políticas norte-americanas, era simplesmente porque tinham sido forjados pela disciplina linear da palavra impressa. O livro treinava nos leitores a concentração e a atenção prolongada, ao passo que a televisão habitua os espectadores à distração e dispersão contínua.

Os livros de Birkerts e de Carr partem de uma verificação comum, e que certamente também é nossa. Os jovens deixaram de apreciar literatura e não leem livros. Birkerts conta como lecionando no outono de 1992 um curso intitulado "The American Short Story" a alunos de graduação, se deparou com uma indiferença estranha. A turma era composta de alunos inteligentes, diligentes, mas os textos selecionados de textos de Washington Irving, Hawthorne, Poe, James e Jewett, não suscitaram de modo algum o suposto fascínio ou sequer o interesse dos estudantes. Nem o vocabulário, nem a sintaxe, nem o enredo constituíam dificuldades. Entendiam tudo, só que o problema era "o todo" (the whole thing). Escapava-lhes o sentido das novelas, como se pertencessem a um outro mundo. O problema não era este ou aquele autor, o problema residia no facto de "a experiência coletiva dos estudantes, nascidos na primeira metade da década de 70, ter feito de uma grande parte da nossa herança cultural algo completamente estranho para eles." ${ }^{\circ 0}$ O que os estudantes não entendiam era o que estava debaixo do vocabulário e da sintaxe, e isso era "todo um sistema de crenças, valores e aspirações culturais" 91.

Os textos eram fruto de um mundo e de uma época a que os meios eletrónicos de comunicação puseram fim. A incompreensão dos alunos, ou melhor, o desinteresse e fastio que sentiam por aquelas histórias, não resultava de uma qualquer circunstância particular, mas sim de uma mudança sistémica de atitudes e de assunções, que Birkerts situa algures na década de 50 do século passado, quando a televisão entrou nos lares americanos e as pessoas começaram a viver em dois mundos paralelos, um em que viviam e outro em que podiam entrar sempre que buscavam um intervalo ou uma fuga da vida que levavam. ${ }^{92}$

Os livros pertencem ainda, de algum modo, ao mundo que o homem habitou ao longo de milénios, em que o espaço e o tempo delimitavam a existência individual e constituíam poderosas barreiras à comunicação. A imediatez e a

\footnotetext{
90 Birkerts, 2006, p. 19.

91 ibidem.

92 idem, p. 214.
} 
omnipresença das comunicações eletrónicas vieram alterar profundamente a maneira de estar e de viver dos indivíduos e das comunidades. Birkerts escreve que hoje em dia haverá muitas pessoas que nunca nas suas vidas passarão pela experiência de estar num local isolado, no meio de árvores e de pedras, a mais da distância do grito de outra pessoa, sem qualquer dispositivo de telecomunicação, forçadas à lenta e dura passagem do tempo, experiência essa que era a norma na vida das pessoas em épocas passadas. As formas de viver que regularam o dia a dia dos indivíduos e se tornaram bens culturais passados de geração em geração tornaram-se, de repente, em grande medida irrelevantes. Hoje estamos permanentemente conectados, graças aos novos meios, com mais e mais pessoas, fisicamente ausentes, enquanto vamos diminuindo as relações presenciais, face a face. ${ }^{93}$

Imerso num livro, o leitor encontra-se só, envolto num espaço e num tempo que é só dele. É que a leitura atenta (deep reading) de um livro se distingue em muito da comunicação eletrónica. A ordem tipográfica é linear, obedece às regras da sintaxe, que estabelece as coordenadas da linguagem com sentido. A comunicação impressa exige uma participação ativa por parte do leitor, nomeadamente uma atenção dedicada, pois que ler é um ato de tradução de símbolos e de interpretação. Por outro lado, a tipografia determina um eixo temporal: a ordem de leitura, ao longo das linhas, de cima para baixo, e o voltar das páginas, constitui um movimento contínuo em frente, servindo os conteúdos lidos previamente de fundamento aos conteúdos posteriores. Acrescente-se que os materiais impressos são extáticos, é o leitor que avança e não o livro. O ritmo de avanço é lento. Ou seja, as características físicas do livro estão de acordo com o sentido tradicional de história.94

A ordem eletrónica é, em muitos aspetos, o oposto. A informação não passa de um setor privado para outro, mas por uma rede pública, onde passam outras informações no âmbito de um circuito de múltiplas conexões. Por outro lado, a comunicação eletrónica é passiva, no caso da televisão, ou interativa, no caso do computador. Os conteúdos são efémeros; mudam-se e apagam-se com o pressionar de um botão ou de uma tecla. O ritmo é rápido, caracterizado por

\footnotetext{
93 idem, p. 214-215.

94 idem, 122.
} 
saltos e interrupções, e o movimento procede lateralmente por associações, mais do que por uma cumulação vertical.

As consequências da mudança de como lemos são vastas e profundas. Desde logo assistimos a uma erosão da linguagem. Os meios eletrónicos de comunicação exigem uma enorme simplificação da linguagem, designadamente da sintaxe e da semântica. As complexidades características da escrita tipográfica dão lugar a uma linguagem telegráfica. Há um empobrecimento vocabular e uma platitude sintática. É o triunfo total da denotação sobre a conotação. Não há mais lugar aos duplos sentidos, à ambiguidade, ao paradoxo, à ironia, ao humor, à subtileza. Exige-se mesmo que o que é complexo e longo seja transposto para uma formulação simples e breve, inevitavelmente à custa de perdas importantes de significado. É claro que a literatura é uma das vítimas desta erosão linguística. Não é preciso que seja um texto de um dos clássicos, por exemplo Francisco Manuel de Melo, Rodrigues Lobo, Bernardes ou Vieira, mesmo um texto literário contemporâneo é incompreensível a muitos dos estudantes universitários.

Outra das consequências da leitura eletrónica é o esbatimento da perspetiva histórica. Um livro não é apenas o seu conteúdo, é também um objeto físico com múltiplas indicações sobre a sua origem e o seu passado. O tipo de encadernação, o uso que denota, se muito ou pouco lido, sublinhado ou anotado, a localização numa biblioteca, tudo isso empresta uma profundidade histórica à leitura tipográfica, que está ausente na leitura eletrónica. Um livro insere-se sempre numa linha histórica, de uma editora, uma coleção, de um passado de pertença, que constitui um horizonte temporal inerente à sua leitura. Por sua vez, a leitura eletrónica é feita num presente perpétuo, uniforme, igual para todos os textos, que, desse modo, ficam descontextualizados.

Finalmente, Birkerts observa que no fim desta evolução deparamos com o declínio da privacidade individual. Efetivamente, há a tendência de aceitar a vida tornada cada vez mais transparente pelos meios eletrónicos. Os sistemas eletrónicos estão sempre ligados, registando continuamente os nossos passos e ações. A vida privada surge como algo opaco, pertencendo ao passado. As paredes e as portas das nossas habitações perdem relevância; o mundo entra em nossa casa pelas redes que nos mantém em permanente comunicação, comunicação essa que acaba sempre por nos expor. 
Não deixa de ser curioso que Birkerts saliente o definhamento do sentido de privacidade muito antes da Web 2.0, dos blogues e do facebook. Há jovens hoje que não entendem o que é a privacidade, que apenas distinguem o que é e o que não é segredo, sendo público tudo o que não é segredo.

Creio que este é o ponto central da elegia que Birkerts faz da cultura tipográfica. À medida que os indivíduos se ligam eletronicamente uns aos outros, à medida que todos se encontram online, há uma retração da subjetividade individual e, portanto, também uma perda da privacidade essencial à autoconsciência enquanto foro de autonomia e espontaneidade próprias. Para Birkerts a opção é clara: "o que se ganha em acesso e em eficiência é à custa da autoconsciência subjetiva". 95

A conectividade geral e permanente tem como contrapartida o sacrifício da vida própria do eu isolado. Os paladinos das novas tecnologias esquecem que os meios, além de extensões dos nossos sentidos, são também as extensões dos sentidos dos outros e que o resultado desse contacto super-mediado é a erradicação final da solidão individual que até aqui determinava os termos da existência de cada pessoa. ${ }^{96}$

Birkerts aplica a teoria benjaminiana da aura ao indivíduo. Será que cada um de nós enquanto indivíduo possui uma aura tal como os objetos de arte, uma presença única que só se manifesta no aqui e agora da localização espaciotemporal? Se sim, se efetivamente cada um de nós é dotado de uma aura própria, então o que a reprodução técnica faz às obras de arte, a depreciação da qualidade da sua existência única, no aqui e agora, ${ }^{97}$ também a miríade de meios de comunicação que envolvem o indivíduo e o conectam a outros lugares e tempos acaba por desvalorizar a presença real do indivíduo. ${ }^{98}$

Dantes, antes da introdução dos meios de comunicação, as interações humanas eram face a face, em presença. A comunicação era fundada na presença. Originariamente não havia um hiato entre a pessoa e a comunicação. Dantes, antes do megafone e do telefone, o mais longe que a voz humana ia era a distância

\footnotetext{
95 p. 220.
}

96 ibidem.

97 "Die Umstände, in die das Produkt der technischen Reproduktion des Kunstwerks gebracht werden kann, mögen im übrigen den Bestand des Kunstwerks unangetastet lassen - sie entwerten auf alle Fälle sein Hier und Jetzt."

98 p. 226. 
de um grito. O que os meios de comunicação fazem é quebrar este vínculo direto entre presença e comunicação.

Voltando à doutrina da aura, o que verificamos é que, em última instância, o efeito de todas as mediações do real, e isso significa o afastamento e a fragmentação de uma ligação direta ao mundo, pode ser comparada à depreciação da obra de arte original pela reprodução técnica. Os diversos avanços tecnológicos não só têm como contrapartida direta a diminuição da função original99 - tal como o telefone esbateu o poder e a imediatez do diálogo humano -, mas também acaba por destruir, pelo menos parte, da autoridade fundamental do próprio ser humano. Com a comunicação total e permanente o que está em jogo é nada menos que a erosão da presença humana, tanto no que respeita à autoridade do indivíduo como da própria espécie humana. ${ }^{100}$

Birkerts acaba por confessar o receio de estarmos, enquanto cultura, a tornar-nos mais superficiais (shallower), de que nos estamos a desviar da profundidade da tradição judaico-cristã que via a pessoa como mistério insondável - para nos adaptarmos a uma segurança assente nas conexões laterais. Estamos a desistir da sabedoria, que foi o objetivo último da existência humana durante milénios, para nos convertermos à fé na rede comunicacional. ${ }^{101}$

Em suma, a nossa era da comunicação total desemboca numa "morte da imaginação”, justamente por aniquilar os mundos privados e os substituir por um único mundo plano de conexões. O cenário é o de uma diminuição da cultura, a de uma erosão cultural em larga escala (a large scale leaching away). ${ }^{102}$

O posfácio de 2006 que Birkerts faz numa reedição do livro é menos negro. Passados mais de 10 anos, o autor acabou por aceitar o computador como meio de trabalho (processador de texto) e como meio de comunicação (o uso de email). A escrita do livro ocorreu no início da revolução operada pela introdução da Web gráfica em 1993 e o prefácio é já de uma data posterior à euforia das dot.com e respetivo colapso bolsista, e ao nascimento da Web 2.0 nos inícios

99 "In one of the most perceptive, if least remarked, passages in Understanding Media, McLuhan wrote that our tools end up 'numbing' whatever part of our body they 'amplify'. When we extend some part of ourselves artificially, we also distance ourselves from the amplified part and its natural functions." Nicholas Carr, The Shallows, p. 210.
100 p. 228.
101 ibidem.
102 p. 243. 
da $1^{\text {a }}$ década do novo século. As razões que aponta para a adesão às novas tecnologias são três. A primeira é que não queria gastar as energias em atitudes de recusa pouco práticas. Não valia a pena tornar-se um caso raro de rejeição de tecnologias a bem dizer aceites por toda a gente. A segunda é que desejava continuar a ter uma vida dedicada à escrita e isso impunha manter boas relações com editores, pouco dispostos a aceitar versões de obras escritas à mão ou à máquina, que obrigaria a contratar alguém para as passar a formato digital, já para não falar nos muito mais morosos processos de revisão a que as versões em formato papel obrigam (página quatro, terceiro parágrafo, segunda frase). A terceira razão, a mais importante, foi a educação de dois filhos que entretanto chegavam à adolescência. Embora seja possível criar filhos mantendo-os afastados de dispositivos eletrónicos, a cultura em que vivemos torna isso difícil, e até desagradável, mesmo que seja apenas uma simples tentativa. ${ }^{103}$

Ora aqui paira uma sombra gigante na formação da subjetividade das crianças e adolescentes, nomeadamente na construção da sua capacidade de imaginação. As tecnologias, graças a programas fascinantes e bem desenhados, oferecem um sofisticadíssimo conjunto de opções de escolha, que são superiores ao que uma imaginação individual pode alguma vez conceber. Elas integram e até convidam à participação e interatividade, e estimulam mesmo a criatividade dos utilizadores. Os novos brinquedos concebidos e realizados por equipas multidisciplinares de engenheiros, psicólogos e geeks de toda a espécie, superiorizam-se claramente às criações que brotam de um simples indivíduo. Bombardeadas continuamente por jogos e aventuras com animações fantásticas, as crianças têm dificuldades em voltar a brincar com legos ou a ler um livro de aventuras.

O ponto principal da elegia de Birkerts mantém-se. As novas tecnologias perturbam a formação da subjetividade. É que a subjetividade humana não é algo natural, mas cultural, formado ao longo de milénios, nomeadamente pela solidão, pelos obstáculos postos pela distância física e pela experiência de um tempo continuado de duração e de atenção, não entrecortado por um sem número de sinais e estímulos a dispersar-nos. O que está em causa, pois, é a subjetividade primária, fundamental, de onde nasce genuinamente a arte e o saber.

103 Aqui aplica-se às praticalidades a sentença de Thomas Kuhn sobre as revoluções científicas, de que as teorias vingam ou soçobram consoante os seus seguidores são novos ou velhos. 
Resumindo a advertência de Birkerts é que estamos a perder o mundo originário, tal como o encontrámos, e o correspondente desejo de fazer dele a nossa casa, de o conhecer a ele e aos outros que nele habitam por um presença real e imediata. E estamos a criar um mundo de procuração, um proxy, entre nós e esse mundo primeiro. Ou seja, a conectividade - e a ideologia da conectividade - elimina a oposição, a fricção, aquilo que sempre caracterizou e definiu a experiência humana como tal. Era a velha conceção da vida como luta, a repetida lembrança da mortalidade, que estava na base da tragédia, e da conceção da redenção estimulada pela tragédia. Ora a perda da oposição é a perda da polaridade e, portanto, também a perda do mistério. Não só do mistério das coisas desconhecidas, mas também o mistério do eu e do ser.

Parar um momento no tempo, sentarmo-nos num local calmo, abrir um livro, mergulhar na leitura, é entrar dentro de nós próprios e oferecer alguma resistência ao mundo da conectividade constante e ubíqua.

2. As elegias culturais de Birkerts podem ser obviamente vistas, e desvalorizadas, como uma reedição contemporânea de elegias passadas de mundos que desaparecem face às mudanças temporais. E mesmo a alegação de que hoje o caso é diferente, mais grave, de que é a própria identidade humana que está em jogo, pode ser enfrentada com o verso de Camões que "afora este mudar-se cada dia, / Outra mudança faz de mor espanto:/ Que não se muda já como soía." Podem também ser desmontadas a vários níveis, de que esse mundo natural e original nunca foi tão direto e presencial como o autor quer fazer crer, nem a teia de conexões em que hoje vivemos é o casulo artificial que nos isola desse mundo primeiro e natural.

Mas as elegias não são apenas lamento; constituem também um elemento identitário crucial em épocas de mudanças profundas. É certo que a ligação que fazem ao passado é sob o signo da perda, do que não vinga na atualidade e acaba por morrer. Contudo, o memento mori elegíaco não é saudosismo inane, antes consciência da necessidade de preservar da usura inexorável do tempo valores intemporais. Mal vai uma época onde as elegias não têm mais lugar. Com efeito, a confiança cega no futuro, na admirável capacidade da tecnologia, em que o passado é propositadamente esquecido porque escolho ao avanço 
do progresso, é não apenas temeridade juvenil, mas também aleijão intelectual grave, na medida em que oblitera a dimensão histórica da existência humana.

O sentimento da perda expresso pelas elegias, estando virado para o passado, constitui um salutar estado de cautela e de prevenção face ao presente e ao futuro. A tecnologia torna o homem qual aprendiz de feiticeiro, lidando com forças tremendas que não é capaz de controlar. Hans Jonas preconizou justamente uma ética de responsabilidade para enfrentar os desafios colocados pela tecnologia. ${ }^{104}$ Tal ética é a de uma atitude de receio e de cautela no uso e manejo das potencialidade tecnológicas, precavendo imprevisíveis, mas possíveis consequências nefastas desse uso. Jonas refere em particular a ameaça atómica de um suicídio coletivo de toda a humanidade e o risco biotecnológico da alteração da identidade humana. Porém, os riscos que o homem presentemente enfrenta não se restringem a alterações duras, tipo hardware, mas estendem-se a modificações de configuração da sua maneira de pensar e sentir, ou seja, a alterações tipo software. Birkerts chama a atenção para o risco que o uso das novas tecnologias de informação e comunicação envolve, nada menos que uma perda da subjetividade humana tal como tem sido forjada ao longo de milénios. Portanto, as suas elegias gutenberguianas não são apenas um lamento relativo a um forma específica de transmissão da cultura, são também um sério aviso ao modo como essas tecnologias são usadas no quotidiano humano, em particular na educação de crianças e jovens.

104 Hans Jonas, 1979, Das Prinzip Verantwortung: Versuch einer Ethik für die technologische Zivilisation. Frankfurt: Suhrkamp. 


\section{BIBLIOGRAFIA}

Walter Benjamin, 1939, "Das Kunstwerk im Zeitalter seiner technischen Reproduzierbarkeit". http://walterbenjamin.ominiverdi.org/wp-content/kunstwerkbenjamin.pdf

Sven Birkerts, 1994, The Gutenberg Elegies: the fate of reading in an electronic age, Boston: Faber and Faber

Nicholas Carr, 2008, "Is Google making us stupid?", publicado na revista Atlantic Monthly de Julho.

Nicholas Carr, 2010, The shallows: what the Internet is doing to our brains, New York: W.W. Norton.

Hans Jonas, 1979, Das Prinzip Verantwortung: Versuch einer Ethik für die technologische Zivilisation. Frankfurt: Suhrkamp.

Neil Postman, 1986, We are amusing ourselves to death: public discourse in the age of show business, New York: Penguin Books. 